\title{
HLA DR4 and rheumatoid arthritis in Japanese people
}

\author{
HIROO MAEDA, 1 TAKEO JUJI, ${ }^{1}$ HIROSHI MITSUI, 2 \\ HIDEKICHI SONOZAKI ${ }^{2}$ AND KATSUHIKO OKITSU ${ }^{2}$
}

From the ${ }^{1}$ Blood Transfusion Serivce and the ${ }^{2}$ Department of Orthopedic Surgery, Tokyo University Hospital, Tokyo, Japan

SUMMARY Eighty-eight Japanese patients with rheumatoid arthritis and 104 normal Japanese persons were typed for HLA A, B, C, and DR antigens. The frequency of HLA DR4 was $70.5 \%$ in patients compared with $46.1 \%$ in normal controls $(\mathrm{P}<0.001)$. However, a sex difference in the frequency of HLA DR4 in patients was noted. HLA DR4 was found in $80.6 \%$ of male patients, which was highly significant compared with controls $(\mathrm{P}<0.0005)$, while only a borderline increase to $60.5 \%$ was found in female patients $(\mathrm{P}<0.05)$. In addition, the frequency of HLA DR2 was remarkably low in male patients. These suggest the possible heterogeneity of rheumatoid arthritis in Japanese.

Since a strong association between ankylosing spondylitis and HLA B27 was reported, ${ }^{1}$ HLA antigens in patients with other arthropathies have been extensively studied. Ankylosing spondylitis and its related diseases were confirmed to be associated with HLA-B27 in different ethnic groups. ${ }^{2-4}$ In rheumatoid arthritis most studies have failed to show an association with HLA A or B antigens. ${ }^{5-9}$ However, Stastny found an increased frequency of rheumatoid patients whose lymphocytes did not response to one type of stimulator lymphocyte, now known as HLA Dw4, in mixed lymphocyte culture. ${ }^{10}$ Two other investigators confirmed this evidence in separate series of Caucasian patients. ${ }^{11} 12$

HLA DR antigens are the serologically detectable HLA D related antigens present on B lymphocytes and monocytes. By HLA DR typing an increase of HLA DR4 was also established in Caucasian patients with rheumatoid arthritis. ${ }^{13-16}$

In the study reported here Japanese patients with rheumatoid arthritis were typed for HLA DR antigens to see whether the same association was present as was the case in the Caucasian patients.

\section{Materials and methods}

Eighty-eight patients who were diagnosed as classical or definite rheumatoid arthritis according to the

Accepted for publication 4 July 1980

Correspondence to Dr Hiroo Maeda, Blood Transfusion Service, Tokyo University Hospital, Hongo 7-3-1, Bunkyoku, Tokyo, Japan 113. criteria of the American Rheumatism Association ${ }^{17}$ were selected for this study. All were Japanese, aged from 25 to 73 years old (mean: 50.2), 36 male and 52 female. They have been followed up for 1 to 20 years at the Rheumatology Unit, Department of Orthopaedics, Tokyo University Hospital. All patients were tested for IgM rheumatoid factor at least every 3 months, and none had an abnormal titre of anti-DNA antibody and a positive LE test.

\section{HLA TYPING}

B lymphocytes were purified according to the thrombin-nylon wool method described by Danilovs et al. ${ }^{18}$ Mononuclear cells were separated from heparinised blood by Ficoll-Hypaque gradient centrifugation. After agglutination of platelets and monocytes with thrombin enriched lymphocytes were incubated in a plastic straw column containing nylon wool. Nonadherent cells were collected by dripping medium through the column, and adherent cells were recovered by squeezing the straw. Nonadherent cells were used for HLA A, B, and C typing and adherent cells for HLA DR typing.

The lymphocyte cytotoxicity test was performed according to a modified NIH standard method. ${ }^{19}$ The incubation was for 60 minutes at $37^{\circ} \mathrm{C}$ with antiserum and for 120 minutes at $22^{\circ} \mathrm{C}$ with complement. The rabbit complement was carefully selected not to have cytotoxicity against B lymphocytes.

\section{ANTISERA}

A panel of 100 antisera which covered 8 HLA A, 
17 HLA B, and 6 HLA C specificities was used for HLA A, B, and C typing. All sera for HLA DR typing were absorbed with an equal volume of pooled platelets and confirmed not to react with $T$ lymphocytes. For HLA DR1, DR2, DR3, DR4, DR5, DR7, and DRw8, at least 3 monospecific sera were used. HLA DRw6 and DRw9 were assigned by a positive reaction with anti-DRw $3+6$ and antiDRw7+9 only in the absence of DR3 and DR7, respectively.

Anti-DR4 sera used were $7407 \cdot 3$ (Dr Mervart), CLB EB12 (Dr Engelfriet), 10552 (Dr Matsuyama), and T2297 (authors' laboratory). The former 2 sera were the key sera for DR4 in the 8th International Histocompatibility Workshop. Correlation coefficients among themselves and DR4 antigen are shown in Table 1. The antigen DR4 was assigned by a positive reaction with at least 3 out of the 4 sera.

\section{Results}

All the patients were typed for 31 HLA A, B, and $C$ antigens (Table 2). A borderline increase of HLA Bw54 and HLA Cw1 was found in rheumatoid patients compared with controls. A difference in the frequencies of Bw54 and Cw1 was noted between the 2 sexes. No significant deviations were found in female patients, while Bw54 and Cw1 were found in $33.3 \%$ and $58.3 \%$ of male patients compared with $12.3 \%$ and $32.1 \%$ of controls, respectively. These increases in male patients were significant $(P<0 \cdot 01)$.

Table 3 shows the frequencies of HLA DR antigens in rheumatoid patients and controls. The frequencies of DR4 were increased both in male and in female patients compared with controls. HLA DR4 was found in $80.6 \%$ of male patients and in $63.5 \%$ of female patients. These are significant increases compared with $46.1 \%$ for controls $(\mathrm{P}<0.0005$ for males, $\mathrm{P}<0.05$ for females). The relative risk of HLA DR4 for rheumatoid arthritis was 4.8 in males and 2.0 in females.

The frequency of HLA DR2 was decreased only in male patients. Only 4 out of 36 male patients were HLA DR2 positive compared with 37 out of 104 controls $(\mathrm{P}<0 \cdot 02)$.

Table 1 Correlation coefficients among anti-DR4 sera and with HLA DR4

\begin{tabular}{lllll}
\hline Sera & $7407 \cdot 3$ & CLB EB12 & 10552 & T2297 \\
\hline 7407.3 & - & & & \\
CLB EB12 & 0.90 & - & & \\
10552 & 0.90 & 0.94 & 0.95 & - \\
T2297 & 0.92 & 0.95 & 0.95 & 1.00 \\
HLA DR4 & 0.92 & 0.95 & & \\
\hline $\mathrm{r}=\sqrt{\chi^{2} / \mathrm{n}}$ & & & &
\end{tabular}

Table 2 Percentage frequencies of $H L A A, B$, and $C$ antigens in rheumatoid patients and controls

\begin{tabular}{|c|c|c|c|c|}
\hline \multirow[t]{2}{*}{ HLA antigens } & \multicolumn{3}{|l|}{ Patients } & \multirow{2}{*}{$\begin{array}{l}\text { Controls } \\
(n=106)\end{array}$} \\
\hline & $\begin{array}{l}\text { Male } \\
(n=36)\end{array}$ & $\begin{array}{c}\text { Female } \\
(n=52)\end{array}$ & $\begin{array}{l}\text { Total } \\
(n=88)\end{array}$ & \\
\hline A1 & $5 \cdot 6$ & 1.9 & $3 \cdot 4$ & $1 \cdot 9$ \\
\hline A2 & $36 \cdot 1$ & $44 \cdot 2$ & $40 \cdot 9$ & $48 \cdot 2$ \\
\hline A3 & $2 \cdot 8$ & 0 & $1 \cdot 1$ & 0.9 \\
\hline Aw24 & $55 \cdot 6$ & $69 \cdot 2$ & $63 \cdot 6$ & $56 \cdot 6$ \\
\hline A26 & $19 \cdot 4$ & $26 \cdot 9$ & $23 \cdot 9$ & $21 \cdot 7$ \\
\hline A11 & $22 \cdot 2$ & $15 \cdot 4$ & $18 \cdot 2$ & $14 \cdot 2$ \\
\hline Aw31 & $16 \cdot 7$ & 9.6 & $12 \cdot 5$ & $17 \cdot 0$ \\
\hline Aw33 & 19.4 & $15 \cdot 4$ & $17 \cdot 0$ & $13 \cdot 2$ \\
\hline B7 & $2 \cdot 8$ & $17 \cdot 3$ & $11 \cdot 3$ & $11 \cdot 3$ \\
\hline B8 & 0 & 0 & 0 & 0 \\
\hline B13 & $5 \cdot 6$ & $1 \cdot 9$ & $3 \cdot 4$ & $3 \cdot 8$ \\
\hline B15 & $22 \cdot 2$ & $17 \cdot 3$ & $19 \cdot 3$ & $17 \cdot 9$ \\
\hline B17 & 0 & $3 \cdot 8$ & $2 \cdot 2$ & 0 \\
\hline Bw22 & 0 & $3 \cdot 8$ & $2 \cdot 2$ & $6 \cdot 6$ \\
\hline B27 & 0 & $1 \cdot 9$ & $1 \cdot 1$ & 0 \\
\hline Bw35 & $11 \cdot 1$ & $15 \cdot 4$ & $13 \cdot 6$ & $13 \cdot 2$ \\
\hline B37 & 0 & $1 \cdot 9$ & $1 \cdot 1$ & 1.9 \\
\hline Bw39 & 13.9 & $9 \cdot 6$ & $11 \cdot 3$ & 9.4 \\
\hline Bw44 & 19.4 & $7 \cdot 7$ & $12 \cdot 5$ & $12 \cdot 3$ \\
\hline Bw48 & $2 \cdot 8$ & $5 \cdot 8$ & $4 \cdot 5$ & $6 \cdot 6$ \\
\hline Bw51 & $8 \cdot 3$ & $11 \cdot 5$ & $10 \cdot 2$ & $16 \cdot 0$ \\
\hline Bw52 & $5 \cdot 6$ & $19 \cdot 2$ & $13 \cdot 6$ & $19 \cdot 8$ \\
\hline Bw54 & $33 \cdot 3 * *$ & $17 \cdot 3$ & $23 \cdot 9^{*}$ & $12 \cdot 3$ \\
\hline Bw60 & $11 \cdot 1$ & $13 \cdot 4$ & $12 \cdot 5$ & $16 \cdot 0$ \\
\hline Bw61 & $13 \cdot 9$ & $15 \cdot 4$ & $14 \cdot 8$ & $20 \cdot 8$ \\
\hline Cw1 & $58 \cdot 3^{* *}$ & $36 \cdot 5$ & $45 \cdot 5$ & $32 \cdot 1$ \\
\hline Cw2 & 0 & 0 & 0 & 0 \\
\hline Cw3 & $47 \cdot 2$ & $48 \cdot 1$ & $47 \cdot 7$ & $47 \cdot 3$ \\
\hline Cw4 & $5 \cdot 5$ & $5 \cdot 7$ & $5 \cdot 7$ & 9.4 \\
\hline Cw5 & 0 & 0 & 0 & 0 \\
\hline Cw6 & 0 & $1 \cdot 8$ & $1 \cdot 1$ & $3 \cdot 7$ \\
\hline
\end{tabular}

*P<0.05, **P<0.01 (P not corrected).

Table 3 Percentage frequencies of $H L A D R$ antigens in rheumatoid patients and controls

\begin{tabular}{|c|c|c|c|c|}
\hline \multirow{2}{*}{$\begin{array}{l}\text { HLA DR } \\
\text { antigens }\end{array}$} & \multicolumn{3}{|l|}{ Patients } & \multirow{2}{*}{$\begin{array}{l}\text { Controls } \\
(n=104)\end{array}$} \\
\hline & $\begin{array}{l}\text { Male } \\
(n=36)\end{array}$ & $\begin{array}{l}\text { Female } \\
(n=52)\end{array}$ & $\begin{array}{l}\text { Total } \\
(n=88)\end{array}$ & \\
\hline $\begin{array}{l}\text { DR1 } \\
\text { DR2 } \\
\text { DR3 } \\
\text { DR4 } \\
\text { DR5 } \\
\text { DRw6 } \\
\text { DR7 } \\
\text { DRw8 } \\
\text { DRw9 (7J) }\end{array}$ & $\begin{array}{c}8 \cdot 3 \\
11 \cdot 1^{* *} \\
0 \\
80 \cdot 6^{* * * * *} \\
5 \cdot 6 \\
2 \cdot 8 \\
2 \cdot 8 \\
25 \cdot 0 \\
27 \cdot 8\end{array}$ & $\begin{array}{c}17 \cdot 3 \\
36 \cdot 5 \\
0 \\
63 \cdot 5^{*} \\
1 \cdot 9 \\
5 \cdot 8 \\
0 \\
17 \cdot 3 \\
17 \cdot 3\end{array}$ & $\begin{array}{c}13 \cdot 6 \\
26 \cdot 1 \\
0 \\
70 \cdot 5 * * * \\
3 \cdot 4 \\
4 \cdot 5 \\
1 \cdot 1 \\
20 \cdot 5 \\
21 \cdot 6\end{array}$ & $\begin{array}{c}9 \cdot 6 \\
35 \cdot 5 \\
0 \\
46 \cdot 1 \\
3 \cdot 8 \\
12 \cdot 5 \\
1 \cdot 9 \\
13 \cdot 5 \\
29 \cdot 8\end{array}$ \\
\hline
\end{tabular}

${ }^{*} \mathrm{P}<0.05,{ }^{* *} \mathrm{P}<0.02,{ }^{* * *} \mathrm{P}<0.001,{ }^{* * * * P}<0.0005$.

Rheumatoid patients were subdivided into different groups according to the diagnosis, the year of onset, the presence of rheumatoid factor or rheumatoid nodules, the functional grade, and steroid treatment. The frequencies of HLA DR4 and DR2 are shown in Table 4. There were no significant differences between the frequencies of HLA DR4 in any subgroups compared with the combined data. A borderline negative association in patients was noted between HLA DR2 and steroid treatment $(\mathrm{P}<0.05)$. 
Table 4 Percentage frequencies of HLA DR4 and DR2 antigens in the subgroups of rheumatoid patients

\begin{tabular}{lccc}
\hline & $n$ & $D R 4$ & $D R 2$ \\
\hline Sex & & & \\
$\quad$ Male & 36 & $80 \cdot 6$ & $11 \cdot 1$ \\
$\quad$ Female & 52 & $63 \cdot 5$ & $36 \cdot 5$ \\
Year of onset & & & \\
$\quad>35$ & 10 & $72 \cdot 8$ & $25 \cdot 7$ \\
$\quad<35$ & $61 \cdot 1$ & $27 \cdot 8$ \\
Diagnosis & & & \\
$\quad$ Classical & 49 & $69 \cdot 4$ & $32 \cdot 6$ \\
$\quad$ Definite & 39 & $71 \cdot 8$ & $17 \cdot 9$ \\
Rheumatoid factor & & & \\
$\quad$ Positive & 70 & $72 \cdot 8$ & $25 \cdot 7$ \\
$\quad$ Negative & 18 & $61 \cdot 1$ & $27 \cdot 8$ \\
Nodule & & & \\
$\quad$ With nodule & 22 & $68 \cdot 2$ & $13 \cdot 6$ \\
$\quad$ Without nodule & 49 & $67 \cdot 3$ & $32 \cdot 6$ \\
Functional grade & & & \\
I & 6 & $83 \cdot 3$ & $33 \cdot 3$ \\
II & 35 & $68 \cdot 6$ & $22 \cdot 8$ \\
III & 36 & $72 \cdot 2$ & $30 \cdot 5$ \\
IV & 11 & $63 \cdot 6$ & $18 \cdot 2$ \\
Therpy & & & \\
Steroid & 18 & $72 \cdot 2$ & $5 \cdot 5 *$ \\
$\quad$ Nonsteroid & 70 & $70 \cdot 0$ & $31 \cdot 4$ \\
Total & 88 & $70 \cdot 5$ & $26 \cdot 5$ \\
\hline
\end{tabular}

$* \mathbf{P}<0.05$.

\section{Discussion}

This report provides evidence that rheumatoid arthritis in Japanese people is strongly associated with HLA DR4.

So far the HLA Dw4 and DR4 association has been well established only in Caucasian patients with rheumatoid arthritis. ${ }^{10-16}$ Since most studies have failed to show a strong association between rheumatoid arthritis and HLA A, B, and C antigens, ${ }^{5-9}$ the HLA D or DR allele has been thought to be primarily concerned. This applies also to other autoimmune diseases such as coeliac disease, Graves's disease, and juvenile diabete mellitus. ${ }^{3}$

The association between HLA antigens and these diseases has been generally thought to be due to the linkage disequilibrium between the HLA gene and the genes which predispose to the diseases. If so, it is important to establish whether the same association is present in other ethnic and racial groups having different distributions of HLA antigens.

In a joint report on rheumatoid arthritis during the 8th International Histocompatibility Workshop a strong association of rheumatoid arthritis with HLA DR4 was found in Japanese, Hungarians, Latin Americans, and Caucasians. ${ }^{16}$ However, there was some difficulty in assigning HLA DR4 in Orientals, because most of the anti-DR4 sera used in the workshop also contained activity for HLA DRw9, which cross-reacts with DR4 and DR7 and is common in Japanese. ${ }^{20}$

In this experiment HLA DR4 was determined accurately by 4 monospecific sera which correlated highly among themselves. A significant increase of HLA DR4 in rheumatoid patients was found. Interestingly, however, a sex difference in the frequency of HLA DR4 was present. The overall increased frequency of HLA DR4 was mainly attributable to male patients. The borderline significance of the association in female patients disappeared after the correction of $P$ value by the number of antigens tested. Thus, the HLA DR4 antigen in male and female was given the relative risk of $4 \cdot 8$ and $2 \cdot 0$, respectively. A decreased frequency of HLA DR2 was also noted in male patients. These differences were not reported in Caucasian patients, indicating possible heterogeneity of rheumatoid arthritis among Japanese.

Increased frequencies of HLA Bw54 and HLA $\mathrm{Cw} 1$ are probably due to the effect of linkage disequilibrium with HLA DR4 in the Japanese population.

The same HLA DR antigen is thus associated with rheumatoid arthritis in both Caucasians and Japanese, and is also found in juvenile onset diabetes mellitus in Chinese. ${ }^{21}$ This means that the HLA DR gene and the gene which predisposes to the disease must be very close. The same combinations of antigens between HLA B and C loci, namely, HLA B15 Cw3, Bw35 Cw4, were reported in significant linkage disequilibrium in Caucasians, blacks, and Japanese. ${ }^{22}$ If the disease genes are as tightly linked to the HLA DR locus as the HLA B locus to HLA C, the same association should be found in 2 or 3 of the major racial groups.

Several investigators reported that HLA DR4 was more strongly associated with the severity of the disease ${ }^{1114}$ or the presence of rheumatoid factor. ${ }^{1516}$ However, there was no such correlation in our material.

In conclusion, the increase of HLA DR4 in male patients was significant after the correction of $\mathbf{P}$ value. This suggested possible heterogeneity between Iapanese male and female patients with rheumatoid arthritis. Further study will be needed to show if the sex difference is true or occurred by chance alone.

\section{References}

1 Schlosstein L, Terasaki P I, Bluestone R, and Person C M. High association of an HLA antigen, W27, with ankylosing spondylitis. N Engl J Med 1973; 288: 704-6.

2 Morris R, Metzger A L, Bluestone R, and Terasaki P I. HLA W27, a clue to the diagnosis and pathogenesis of Reiter's syndrome. $N$ Engl J Med 1974; 290: 554-5.

3 Ryder L P, Andersen E, and Svejgaard A. HLA and Disease Registry, Third Report. Copenhagen: Munksgaard, 1979. 
4 Sonosaki H, Seki H, Chang S, Okuyawa M, and Juji T. Human lymphocyte antigen, HL-A27, in Japanese patients with ankylosing spondylitis. Tissue Antigens 1975; 5: 131-6.

5 Lies R B, Messner R P, and Troup G M. Histocompatibility antigens in rheumatoid arthritis. Arthritis Rheum 1972; 15: 524-9.

- Nyulassy S, Ravingerova G, Zvarova E, and Buc M. HL-A antigens in rheumatoid arthritis. Lancet 1974; i: 450-1.

? Kueppers F, Brackertz D, and Muller-Eckhardt C. HL-A antigens in sarcoidosis and rheumatoid arthritis. Lancet 1972; ii: 1425.

8 Gibson D J, Carpenter C B, Stillman J S, and Shur P H. Re-examination of histocompatibility antigens found in patients with juvenile rheumatoid arthritis. $N$ Engl J Med 1975; 293: 636-8.

9 Mitsui H, Juji T, Sonosaki H, Seki H, and Watanabe N. Distribution of HLA-B27 in patients with juvenile rheumatoid arthritis. Ann Rheum Dis 1977; 26: 86-7.

10 Stastny P. Mixed lymphocyte cultures in rheumatoid arthritis. J Clin Invest 1976; 57: 1148-57.

11 McMichael A J, Sasazuki T, McDevitt H O, and Payne R O. Increased frequency of HLA-Cw3 and HLA-Dw4 in rheumatoid arthritis. Arthritis Rheum 1977; 20: $1037-42$.

12 Thomsen M, Morling N, Snorrason E, Svejgaard A, and Sorensen S F. HLA-Dw4 and rheumatoid arthritis. Tissue Antigens 1979; 13: 56-60.

13 Stastny P. Association of the B-cell alloantigen DRw4 with rheumatoid arthritis. $N$ Engl $J$ Med 1978; 298: 869-71.
14 Roitt I M, Corbett M, Festenstein H, Jaraquemada D, Parasteriadis C, Hay F C, and Nineham L J. HLA-DRw4 and prognosis in rheumatoid arthritis. Lancet 1978; i: 990.

15 Dobloug J H, Førre O, and Thorsby E. HLA-DRw4 and rheumatoid arthritis. Lancet 1979 ; i: 548-9.

16 Stastny P. Joint report on rheumatoid arthritis. In: Terasaki P I, ed. Histocompatibility Testing 1980. Copenhagen: Munksgaard, 1980 : in press.

17 Ropes M W, Bennet G A, Cobb S, Jacox R, and Jessar R A. 1958 revision of diagnostic criteria for rheumatoid arthritis. Bull Rheum Dis 1958; 9: 175-6.

18 Danilovs J, Teraskai P I, Park M S and Ayoub G. B lymphocyte isolation by thrombin-nylon wool. In: Terasaki Pl, ed. Histocompatibility Testing 1980. Copenhagen: Munksgaard, 1980: in press.

19 Terasaki P I, McClelland J, Park M S, and McCurdy B. Microlymphocyte cytotoxicity test. In: Ray, J G, Hare D B, Petersen P D, Kayhoe D E, eds. Manual of Tissue Typing Techniques. Bethesda: NIH, 1974: 67-72.

20 Maeda $H$ and Juji T. A newDR antigen crossreactive with DRw4 and DRw7. In: Terasaki P I, ed. Histocompatibility Testing 1980. Copenhagen: Munksgaard, 1980: in press.

21 Maeda H, Takeuchi F, Juji T, Akanuma A, Kasuga M, Lee YS, Kosaka K, and Tsai S H. HLA-DRw3 in juvenile onset diabetes mellitus in Chinese. Tissue Antigens 1980; 15: 173-6.

22 Pickbourne P, Piazza A, and Bodmer W F. Population analysis. In: Bodmer W F, Batchlor $J$ R, Bodmer J G, Festenstein H, Morris P J, eds. Histocompatibility Testing 1977. Copenhagen: Munksgaard, 1978: 259-79. 